\title{
Triptolide inhibits the proliferation of cells from lymphocytic leukemic cell lines in association with downregulation of NF-KB activity and miR-16-1*
}

\author{
Hai-tao MENG ${ }^{1}$, Li ZHU ${ }^{1}$, Wan-mao NI ${ }^{1}$, Liang-shun YOU ${ }^{1}$, Jie JIN $^{1}$, Wen-bin QIAN ${ }^{1,2, *}$ \\ ${ }^{1}$ Institute of Hematology, the First Affiliated Hospital, College of Medicine, Zhejiang University, Hangzhou 310003, China; ${ }^{2}$ Xinyuan \\ Institute of Medicine and Biotechnology, College of Life Sciences, Zhejiang Sci-Tech University, Hangzhou 310018, China
}

\begin{abstract}
Aim: To examine the effects of triptolide (TPL) on T-cell leukemia cells and identify their underlying mechanisms. Methods: The cytotoxicity of TPL was assessed by MTT assay. Cell apoptosis was determined using annexin V and DAPI staining and analyzed by flow cytometry or fluorescence microscopy. The activation of caspase pathways and the expression of nuclear factor $\mathrm{kB}$ (NF-kB) p65 were examined by Western blotting. Differences in microRNA (miRNA) expression in Molt-4 and Jurkat cells before and after TPL treatment were identified using microarrays and real-time RT-PCR, respectively.

Results: TPL 20-160 nmol/L treatment potently inhibited cell growth and induced apoptosis in T-cell lymphocytic leukemia cell lines. Molt-4 and Jurkat cells, however, were more sensitive to TPL than L428 and Raji cells. After $24 \mathrm{~h}$ of treatment, bortezomib abrogated the growth of Molt-4 and Jurkat cells with an $\mathrm{IC}_{50}$ of 15.25 and $24.68 \mathrm{nmol} / \mathrm{L}$, respectively. Using Molt-4 cells, we demonstrated that TPL 20-80 nmol/L inhibited the translocation of NF-KB p65 from the cytoplasm to the nucleus and that phosphorylated NF-kB p65 in nuclear extracts was down-regulated in a dose-dependent manner. Similar results were also seen in Jurkat cells but not in L428 cells, as these cells are resistant to TPL and bortezomib (a NF-KB inhibitor). Twenty-three miRNAs were differentially expressed after TPL treatment. Functional analysis revealed that TPL treatment could inhibit expression of miR-16-1* and that transfection of miR-16-1* led to significantly decreased apoptosis induced by TPL.

Conclusion: Our in vitro studies suggest that TPL might be an effective therapeutic agent for treatment of T-cell lymphocytic leukemia and that its cytotoxic effects could be associated with inhibition of NF-KB and down-regulation of miR-16-1*.
\end{abstract}

Keywords: triptolide; T-cell lymphocytic leukemia; NF-kB; miR-16-1*; bortezomib

Acta Pharmacologica Sinica (2011) 32: 503-511; doi: 10.1038/aps.2010.237; published online 28 Mar 2011

\section{Introduction}

Triptolide (PG490, TPL) is a diterpene triepoxide purified from the Chinese herb Tripterygium wilfordii hook F. This compound has been used to treat a variety of autoimmune diseases' it has also been used as an immunosuppressant in patients who have undergone organ and tissue transplantations ${ }^{[1,2]}$. Recent studies analyzing the mechanisms of action of TPL have revealed many properties of this compound that are relevant not only to anti-inflammatory activity but also to anticancer activity. Shamon et $a l^{[3]}$, for example, found that TPL could inhibit the growth of several human cancer-derived cell lines (including breast, prostate, and lung) under cell culture conditions. In hematologic tumors produced by acute myeloid leukemia (AML) cells, TPL treatment caused caspase-dependent

\footnotetext{
* To whom correspondence should be addressed. E-mail qianwenb@yahoo.com.cn

Received 2010-10-07 Accepted 2010-12-31
}

cell death that was mediated via the mitochondrial pathway ${ }^{[4]}$. This treatment also down-regulated Bcr-Abl expression in K562 cells and induced apoptosis in STI571-resistant chronic myeloid leukemia (CML) cells ${ }^{[5,6]}$, suggesting that it lacks cross-resistance with currently available treatments. Our previous study showed that TPL also induced apoptosis in the multiple myeloma (MM) cell line 8226 and in U266 cells. We observed no cytotoxicity in the peripheral blood mononuclear cells examined from normal volunteers ${ }^{[7]}$. Importantly, clinical trials performed in China examining TPL treatment have shown that this drug can induce remission rates of $71 \%$ and $87 \%$ in mononucleocytic and granulocytic leukemia, respectively $^{[8]}$. A succinate salt derivative of TPL (PG490-88) that is water soluble has recently been approved for Phase I clinical trials in France ${ }^{[9]}$. Results show that 3 out of 19 patients diagnosed with refractory or relapsing AML achieved complete remission $^{[10]}$. These data imply a possible clinical application of TPL for leukemia treatment. Data on the ability of TPL to 
induce lymphoblastic leukemia cell death, however, are limited, and underlying mechanisms regulating the action of this compound are not well characterized.

Nuclear factor $\mathrm{\kappa B}$ (NF-kB) plays a critical role in many biological processes, including cell cycle progression, apoptosis, oncogenesis, inflammation, and various autoimmune diseases ${ }^{[11,12]}$. Abnormal constitutive NF-KB activation is widely seen in a number of solid tumors and in diverse types of hematopoietic malignancies, such as $\mathrm{CML}^{[13]}, \mathrm{AML}^{[14]}$, lymphoma $^{[15,16]}$, and acute lymphoblastic leukemia (ALL) ${ }^{[17-19]}$. In particular, constitutively activated NF-KB is found selectively in leukemia stem cells and not in normal hematopoietic stem cells ${ }^{[20]}$. As such, NF-KB may be a potential therapeutic target for the selective eradication of leukemia stem cells. The NF-KB family is composed of five members: p65 (RelA), RelB, c-Rel, p50 (NF-kB1), and p52 (NF-kB2). Activation of p50 homodimers and p50/p65 heterodimers are detected in childhood $\mathrm{ALL}^{[17]}$. A recent study revealed a novel stromal cell function of RelB that promotes T-cell leukemogenesis ${ }^{[21]}$. Furthermore, inhibition of NF-KB activity was found to sensitize ALL cells to interferon $\beta$ treatment ${ }^{[22]}$. Targeting NF- $\mathrm{kB}$ thus provides an attractive strategy for the treatment of lymphoblastic leukemia.

MicroRNAs (miRNAs or miRs) are a small (about 22 nucleotides), highly conserved noncoding class of regulatory RNA molecules expressed in a tissue- and development-specific manner ${ }^{[23]}$. They can play an important role in several types of cancers and in various other aspects of cancer biology ${ }^{[24-26]}$. Currently, extensive studies suggest that several miRNAs may act as oncogenes, tumor-suppressor genes ${ }^{[27]}$, or even modulators of cancer stem cell growth and metastasis ${ }^{[28,29]}$. The theory that miRNAs are involved in cancer is derived from the finding that miR-15a and miR-16-1* are downregulated or deleted in most patients diagnosed with $\mathrm{CLL}^{[30]}$. More interestingly, recent findings indicate that miRNAs can substantially modulate sensitivity and resistance to anticancer drugs ${ }^{[31]}$. A study by Kovalchuk et al ${ }^{[32]}$ shows that miR-451 regulates the expression of multidrug resistance 1 gene and that transfection of miR-451 results in the increased sensitivity of breast cancer cells to doxorubicin. In contrast, miR-214 has been shown to induce cell survival and cisplatin resistance in ovarian cancer cells through inhibiting PTEN translation and activation of the Akt pathway ${ }^{[33]}$. Based on these observations, we hypothesized that miRNAs could affect the response of leukemia cells to TPL. In this study, we examined the effects of TPL on human T-cell leukemia cell lines and investigated the mechanisms underlying TPL-induced cell death. We found that TPL treatment at low nanomolar concentrations potently induced cell death in T-cell lymphocytic leukemia cells in association with inhibition of NF-KB and down-regulation of miR-16-1*.

\section{Materials and methods}

\section{Cell culture and transfection}

The human T-cell lymphocytic leukemia cell lines Molt- 4 and Jurkat, the Burkitt lymphoma cell line Raji, and the Hodgkin's disease cell line L428 were purchased from American
Type Culture Collection (ATCC, Rockville, USA). They were maintained in RPMI-1640 (Hyclone Laboratories, Logan, USA) supplemented with $10 \%$ fetal bovine serum (Hyclone Laboratories), $1 \% \mathrm{~L}$-glutamine and $0.1 \%$ gentamicin at $37{ }^{\circ} \mathrm{C}$ in a humidified incubator containing $5 \% \mathrm{CO}_{2}$ in air. For functional analysis, leukemia cells were washed and resuspended in Opti-MEM I medium (Invitrogen, Carlsabad, USA), and miR16-1* mimics and non-targeting miRNA mimics (GenePharma, Shanghai, China) were used. The miR mimics and control RNA were transfected into the appropriate cells using Lipofectamine 2000 (Invitrogen) according to the manufacturer's instructions. In brief, cells were plated in 6-well plates. For each well, miR-16-1* mimic (100 nmol/L), control RNA (100 $\mathrm{nmol} / \mathrm{L}$ ) and $5 \mu \mathrm{L}$ of Lipofectamine 2000 Transfection Reagent were separately added into $250 \mu \mathrm{L}$ of antibiotic-free OptiMEM I medium and then mixed together to form the transfection complex. The transfection complex was added to cells and incubated for $6 \mathrm{~h}$ before replacing the medium.

\section{Cell viability measurements}

Leukemia cells were plated on 96-well plates at $1.0 \times 10^{5} /$ well and then treated with or without TPL at the indicated dosages for $24 \mathrm{~h}$ and $48 \mathrm{~h}$, respectively. The cell viability was evaluated by 3-(4,5-dimethylthiazol-2-yl)-2,5-diphenyltetrazolium bromide (MTT) assay (Sigma, St Louis, USA) as previously described $^{[34]}$.

\section{Assessment of apoptosis}

Apoptosis was determined using an annexin V-FITC and propidium iodide (PI) apoptosis detection kit (Biouniquer, Suzhou, China), according to the manufacturer's instructions. Prepared cells were analyzed with FACScan flow cytometer and CELLQuest software (Becton Dickinson, Franklin Lakes, USA). To detect chromatin condensation and nuclear fragmentation, cells were fixed with $4 \%$ paraformaldehyde and then stained with $5 \mu \mathrm{g} / \mathrm{mL}$ Hoechst 33258 (Sigma) for $20 \mathrm{~min}$ at room temperature. Apoptotic cells were determined by fluorescence microscopy (Olympus, Tokyo, Japan).

\section{Immunofluorescence studies}

Molt- 4 cells were treated with PBS or TPL at $40 \mathrm{nmol} / \mathrm{L}$ and subjected to immunofluorescence analysis after $24 \mathrm{~h}$. Briefly, cells were plated on glass slides for fixation by $4 \%$ paraformaldehyde for $30 \mathrm{~min}$ at room temperature followed by three washes with PBS. Cells were then incubated with a blocking buffer. The blocking buffer was then removed, and cells were incubated with an anti-human NF-kB p65 subunit antibody (Cell Signaling, Danvers, USA) at $4{ }^{\circ} \mathrm{C}$ overnight. After being washed three times with PBS, slides were incubated with Texas Red-conjugated goat anti-rabbit antibody for $30 \mathrm{~min}$ in the dark at room temperature, and secondary antibody was then removed. Next, slides were stained with $1 \mu \mathrm{mol} / \mathrm{L}$ DAPI (SouthernBiotech, Birmingham, USA) for $5 \mathrm{~min}$ in the dark and washed three times with PBS. They were then mounted on a coverslip and observed under a fluorescence microscope (Olympus, Tokyo, Japan). 


\section{Western blotting}

Cells were harvested and extracted with lysis buffer (Cell Signaling), and nuclear extracts were collected by using a nuclear extraction kit (Millipore, Billerica, USA) according to the manufacturer's instructions. Western blot analysis was performed as described previously ${ }^{[35]}$, with equal protein loading on $12 \%$ SDS-PAGE. The primary antibodies used were caspase-3, poly (ADP-ribose) polymerase (PARP), NF-kB p65, and PhosphorNF-кB p65 (Ser536), all purchased from Cell Signaling Technology. Actin and Lamin B antibodies were used as housekeeping protein control. They were obtained from Santa Cruz Biotechnology (Santa Cruz, USA). After incubation with secondary antibodies (MultiSciences Biotech, Hangzhou, China), blots were revealed by enhanced chemiluminescene (ECL) procedures according to the manufacturer's recommendation.

\section{miRNA microarray expression analysis}

Total RNA was extracted from Molt- 4 and TPL-treated-Molt- 4 cells using TRIzol (Invitrogen) and the RNeasy mini kit (Qiagen, Valencia, USA) according to the manufacturer's instructions. The miRNA microarray analysis was done by KangChen (Shanghai, China). After passing RNA measurement on the Nanodrop instrument, the samples were labeled using the miRCURY' ${ }^{\mathrm{TM}} \mathrm{Hy}^{\mathrm{TM}} / \mathrm{Hy}^{\mathrm{TM}}$ Power labeling kit and hybridized on the miRCURYTM LNA Array (v 14.0). Experiments were carried out in triplicate. Scanning was performed with the Axon GenePix 4000B (Axon, Sunnyvale, USA) microarray scanner. GenePix pro V6.0 was used to read the raw intensity of the image. A $t$ test analysis was conducted comparing Molt- 4 and TPL-treated-Molt- 4 samples, and miRNA with $P$ values $<0.05$ were selected for cluster analysis. The clustering analysis was performed using a hierarchical method as well as average linkage and Euclidean distance metrics ${ }^{[36]}$.

\section{Real-time quantitative RT-PCR of micro-RNA}

The quantitative real-time PCR (qRTPCR) was done by using Hairpin-it miRNAs qPCR Quantitation Kit (GenePharma) according to manufacturer's specified guidelines. Total RNA was isolated by using TRIzol (Invitrogen) and further subjected to DNase (Invitrogen) digestion, following the manufacturer's protocol. The RNA levels were quantified by spectrophotometry. One microgram of total RNA was incubated with DNase I and reverse-transcribed using MMLV reverse transcriptase (Invitrogen). The reverse transcription product was amplified using primer pairs specific for miR-16-1* and miR-138-2*. U6 were used as controls for quantification. qRTPCR was performed using an iQ5 Multicolor Real-Time PCR Detection System (Bio-Rad, Berkeley, USA). The level of each miRNA expression was measured using the $2^{\text {-DeltaDeltaCt }}$ method.

\section{Statistical analysis}

Means were compared using the 2-tailed Student's $t$ test. $P<0.05$ was considered statistically significant in all calculations. All data analyses were performed using GraphPad Prism software version 4.0 (GraphPad, San Diego, USA).

\section{Results}

\section{Effect of TPL on the proliferation of lymphocytic leukemia cells} in vitro

To investigate the effects of TPL on growth and survival of lymphocytic leukemia cells, we treated various leukemia cell lines, including Molt-4, Jurkat, Raji and L428 cells, with increasing concentrations of TPL. As shown in Figure 1, after 1 or $2 \mathrm{~d}$ of treatment, the proliferation of the leukemia cells was significantly inhibited by TPL in a dose-dependent manner, as indicated by MTT assay. Molt- 4 and Jurkat cells, however, were more sensitive to TPL than L428 and Raji cells. Next, we compared the efficacy of TPL with that of bortezomib, a proteasome inhibitor that potently inhibits NF-kB activity. After $24 \mathrm{~h}$ of treatment, bortezomib abrogated the growth of Motl-4 and Jurkat cells with an $\mathrm{IC}_{50}$ of 15.25 and $24.68 \mathrm{nmol} / \mathrm{L}$, respectively. In contrast, a much higher concentration of bortezomib (326.23 nmol/L) was required to achieve a 50\% inhibition in L428 cells.

\section{TPL inhibits NF-KB and induces apoptosis in leukemia cells}

To understand the mechanisms of TPL-induced cell death in leukemic cells, we examined the ability of TPL to induce apoptosis using Annexin V/PI and DAPI staining followed by flow cytometry and fluorescence microscopy analyses, respectively. As shown in Figure 2A, TPL treatment in nanomolar concentration $(80 \mathrm{nmol} / \mathrm{L})$ for $12 \mathrm{~h}$ resulted in apoptosis in a large percentage of cells. L428 and Raji cells, however, were resistant to apoptosis induced by TPL. Analysis of Molt- 4 nuclei after Hoechst staining confirmed that TPL-treated cells exhibited morphologic changes characteristic of apoptosis, such as chromatin condensation and formation of micronuclei (Figure 2B). Next, we tested for molecules that control apoptosis. Western blot analysis was used to confirm our flow cytometric findings by demonstrating that TPL treatment activated two key molecules in the apoptosis pathway, namely, caspase-3 and PARP in Molt-4 and Jurkat cells, but not in L428 cells (Figure 2C).

Several tumor-cell types, including myeloma and leukemia, are known to constitutively express NF-kB through a mechanism yet to be fully defined ${ }^{[37]}$. To determine the role of NF-KB in the process of TPL-induced cell death in lymphoblastic leukemia cells, we treated Molt-4, Jurkat cells, which are sensitive to TPL, and L428 cells, which are resistant to TPL, with the indicated concentrations of TPL. We then used Western blot analysis to determine the possible influence of TPL on the subcellular localization of p65. As shown in Figure 3A, TPL treatment inhibited the nuclear accumulation of p65 in Molt4. Phosphor-NF-kB p65 (Ser536) in nuclear extracts of Molt-4 cells was reduced in a dose-dependent manner. Similar results were seen in Jurkat cells (data not shown). However, this result was not observed in L428 cells. Immunofluorescence staining using a specific antibody against p65 also indicated a decrease in the nuclear translocation of NF-kB in TPL-treated Molt- 4 cells and confirmed the results of the immunoblotting analysis (Figure 3B). Collectively, these data demonstrate that TPL inhibits the nuclear accumulation of NF-kB. 

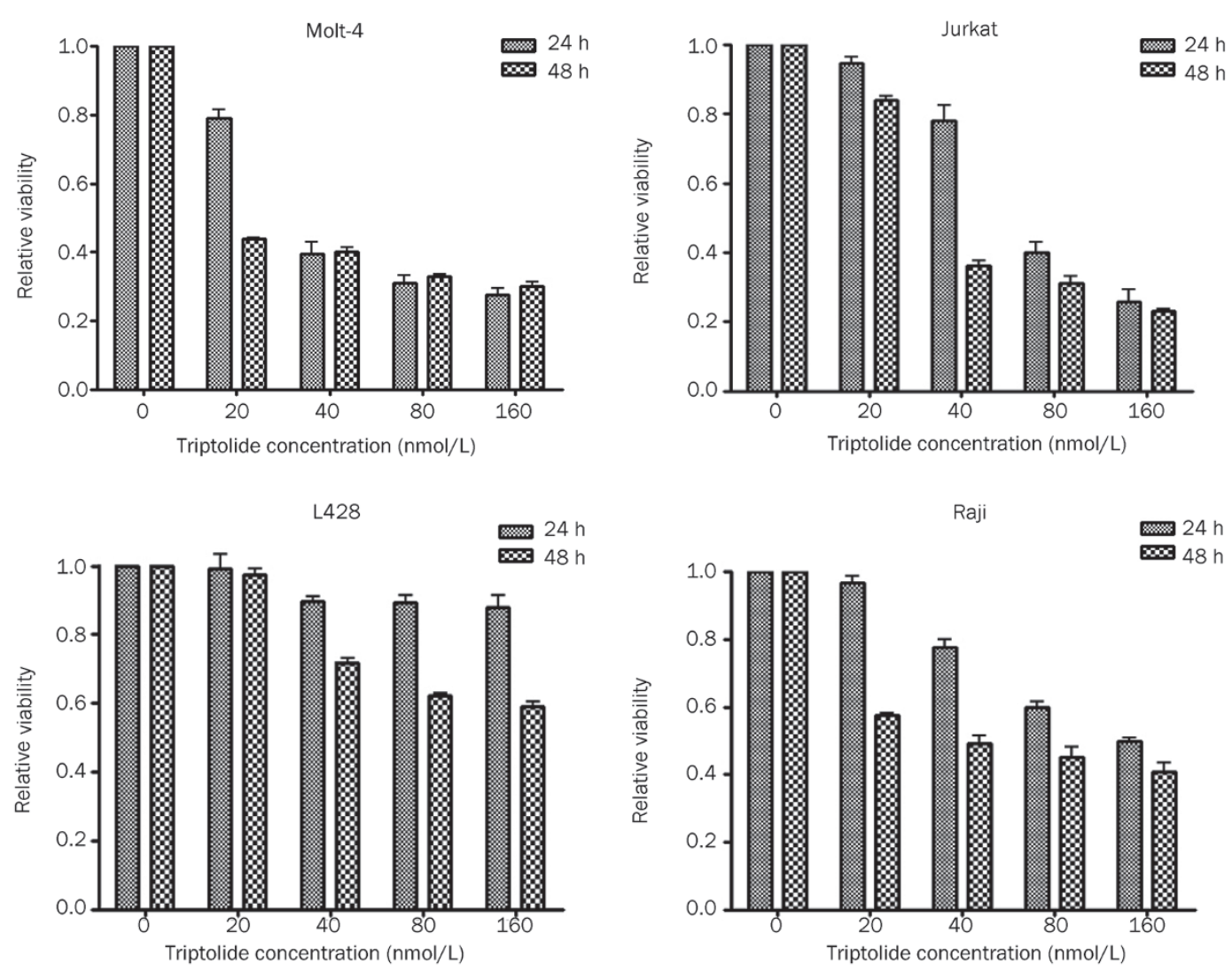

Figure 1. Effect of triptolide on cell growth in lymphocytic leukemia cell lines. Exponentially growing cells were seeded into 96-well plates, and then treated with the indicated concentrations of triptolide for 24 and $48 \mathrm{~h}$, respectively. The proliferation of cells was determined by a MTT assay. Mean \pm SD. $n=3$ independent experiments. bars, SD.

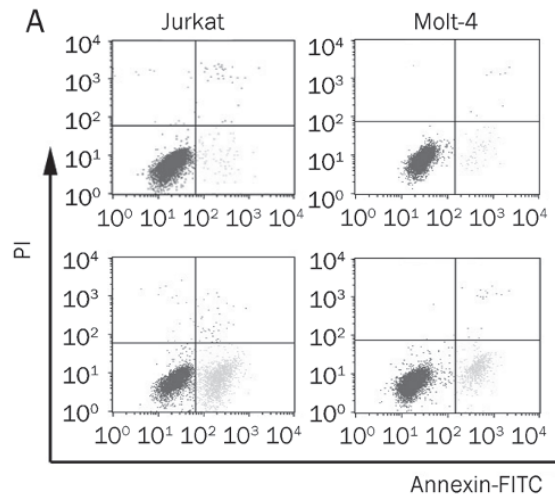

B

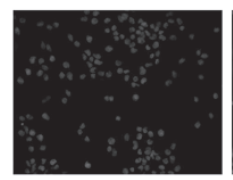

0

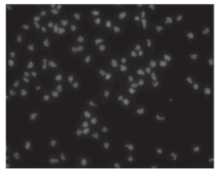

20
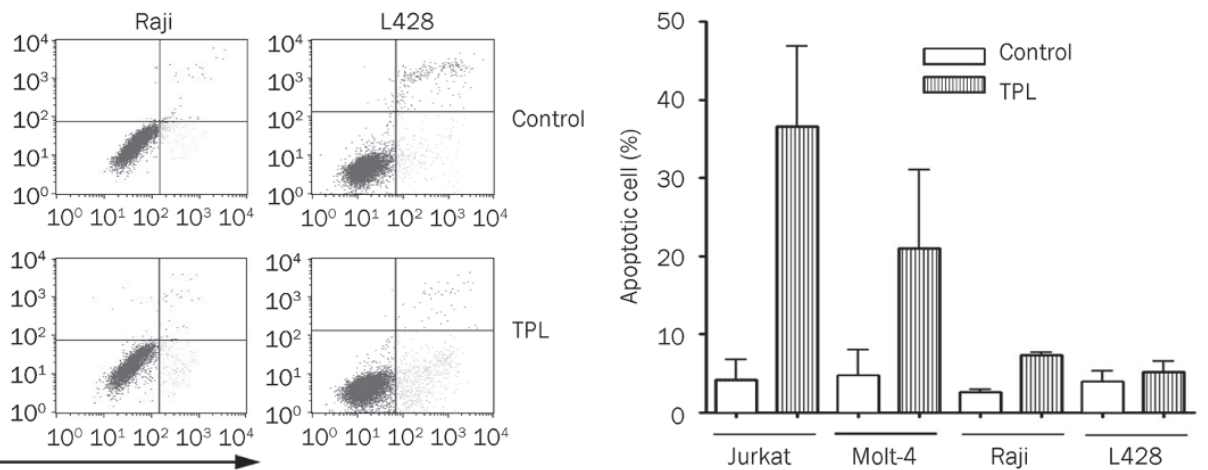

Triptolide concentration $(\mathrm{nmol} / \mathrm{L})$

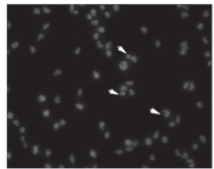

40

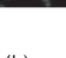

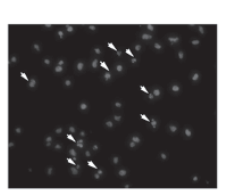

80

C
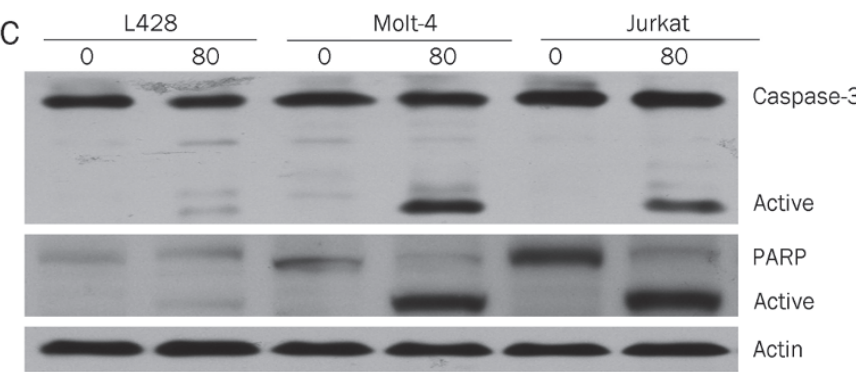

Figure 2. Apoptosis induced by triptolide. (A) After treatment with triptolide at $80 \mathrm{nmol} / \mathrm{L}$ for $12 \mathrm{~h}$, cells were collected and detected by the annexin-V/ propidium iodide (PI)-staining method. The results were expressed as mean $\pm \mathrm{SD}(n=3)$. (B) After treatment with triptolide at indicated concentrations for $12 \mathrm{~h}$, Molt-4 cells were stained with Hoechst 33258 and then observed under a fluorescence microscope. Arrows, apoptotic nuclei. (C) Leukemia cell lines were incubated with $80 \mathrm{nmol} / \mathrm{L}$ of triptolide for $12 \mathrm{~h}$, and then cell extractions were subjected to Western blotting analysis using anti-caspase-3 and PARP antibodies. The results are the representatives of three separate experiments. 
A
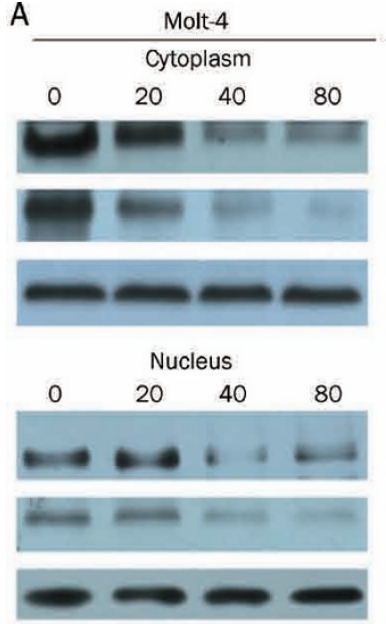

\begin{tabular}{lll}
\multicolumn{3}{c}{ L428 } \\
\hline \multicolumn{4}{c}{ Cytoplasm } \\
$0 \quad 20 \quad 40 \quad 80$
\end{tabular}

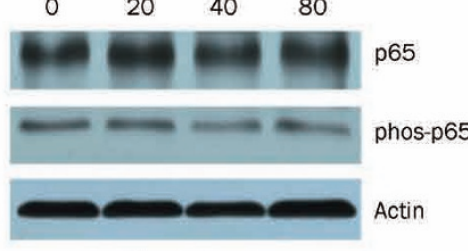

B
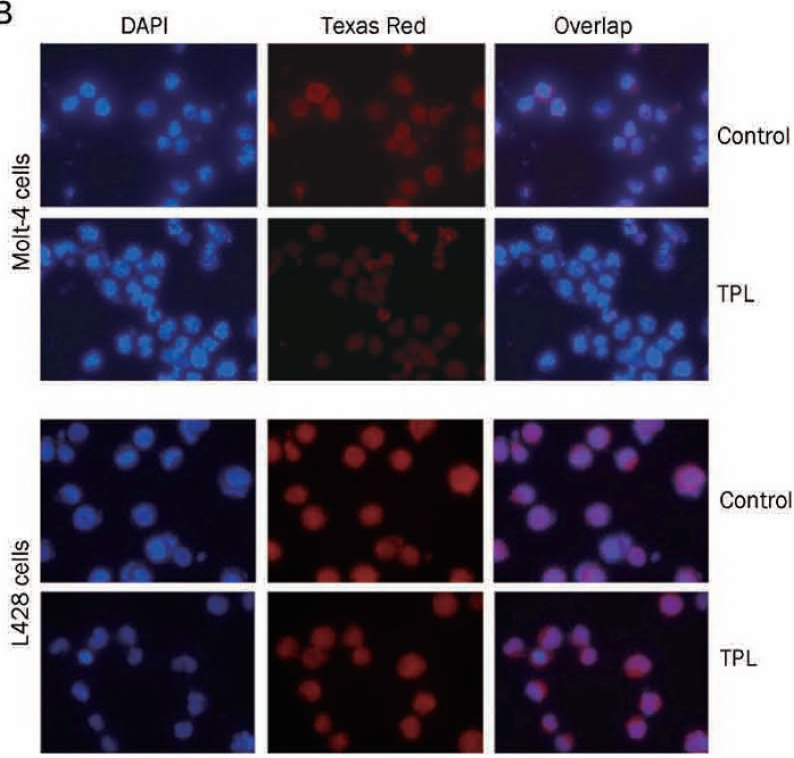

Figure 3. Triptolide inhibits the expression of NF-KB and the accumulation of p65 in nucleus. (A) Cells were treated with triptolide at the indicated concentrations for $24 \mathrm{~h}$. The nuclear and cytoplasm fractions of cells were harvested, and then were analyzed by Western blotting using anti-nuclear factor kB (NF-kB) p65 and phos-p65 antibodies. The blots were blotted with actin or lamin $B$ antibody to control for sample loading. Results shown are representative of three separate experiments. (B) Cells treated with $40 \mathrm{nmol} / \mathrm{L}$ of triptolide were fixed, permeabilized, and then subjected to immunofluorescent double staining with antibody against p65 subunit of NF-kB by Texas Red. Nuclei were counterstained with DAPI.

Comparative analysis of miRNA expression profile in Molt-4 cells before and after TPL treatment

We analyzed the miRNA expression profiles in the human leukemia Molt- 4 cell line and TPL-treated Molt- 4 cells. The clusters analysis revealed that the Molt- 4 cells treated with TPL demonstrated significant changes in miRNA expression. We identified 23 miRNA genes (17 up-regulated and 6 downregulated) that were differentially expressed $(P<0.05)$ in the TPL-treated Molt- 4 cells, compared to the parental Molt- 4 cells (Figure 4A). Among these identified miRNAs, miR-16 ${ }^{[38]}$ and
miR-138 family members ${ }^{[39-40]}$ have been previously implicated in tumorigenesis and cancer cell death. As such, qRT-PCR was used to determine the expression differences of miR-16-1* and miR-138-2* in the paired lymphocytic leukemia cell lines. Upregulation of miR-138-2* and downregulation of miR-16-1* by TPL in a time- and dose-dependent manner was observed in Molt-4 cells (Figure 4B and C). Similar results were obtained in Jurkat cells (Figure 4D). These results confirmed the microarray findings for miR-138-2* and miR-16-1*.

\section{Downregulation of miR-16-1* may contribute to TPL-induced cell death}

To investigate the involvement of miR-16-1* down-regulation in TPL-induced cell death, functional analyses were performed to test the effects of miR-16-1* on cell apoptosis. As shown in Figure 5, ectopic transfection of miR-16-1* mimics led to significantly decreased apoptosis of TPL-treated Molt- 4 cells (23\% vs $17 \%, P<0.05)$, suggesting that miR-16-1* may provide partial protection against the cytotoxicity of TPL. It should be noted that transfection of negative control oligonucleotides into Molt- 4 cells did not affect their sensitivity to TPL. Collectively, out data indicate that downregulation of miR-16-1* may be associated with the cytotoxicity of TPL in T-cell lymphocytic leukemia cells.

\section{Discussion}

Acute lymphocytic leukemia in adults is the most aggressive neoplastic disorder of lymphocytes. Over the last several decades, survival rates of the patients have remarkably improved due to progress in therapeutic protocols; however, a higher proportion of the patients cannot expect long-term remission because of frequent relapse with poor clinical outcome. As such, novel biological therapeutics need to be developed, either alone or in combination with conventional chemotherapy ${ }^{[18]}$. NF-kB is a major factor underlying malignant $\mathrm{T}$-cell transformation, drug resistance, and apoptosis. It was found that adult T-cell leukemia cells possess constitutively

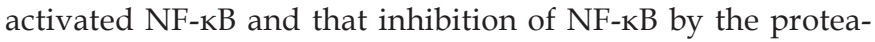
some inhibitor bortezomib or by Bay 11-7082 induces cell death in adult T-cell leukemia cells ${ }^{[41-43]}$. We became interested in TPL because it was reported that TPL is a potent inhibitor of NF-KB activation. In this regard, Qiu et $a l^{[44]}$ showed that TPL at $200 \mathrm{ng} / \mathrm{mL}$ and $1000 \mathrm{ng} / \mathrm{mL}$ caused nearly complete inhibition of IкBa protein expression in activated T-cells. In the present study, we demonstrate that TPL at low nanomolar concentration (20-80 nmol/L) potently inhibits cell growth of T-cell lymphocytic leukemia cell lines and induces apoptosis, as demonstrated by annexin $\mathrm{V}$ staining and Hoechst staining. The cleavage of caspase-3 and PARP was observed in the T-cell lymphocytic leukemia cells, suggesting that the activation of caspase pathway is involved in TPL-induced apoptosis. These results concur with those obtained in AML cells treated with TPL ${ }^{[4]}$. We also show that the responses appear to be dependent upon inhibition of NF-kB activity, as treatment with TPL induced a dose-dependent decrease of phospho-p65 level in T-cell leukemia cell lines accompanied by a reduced 


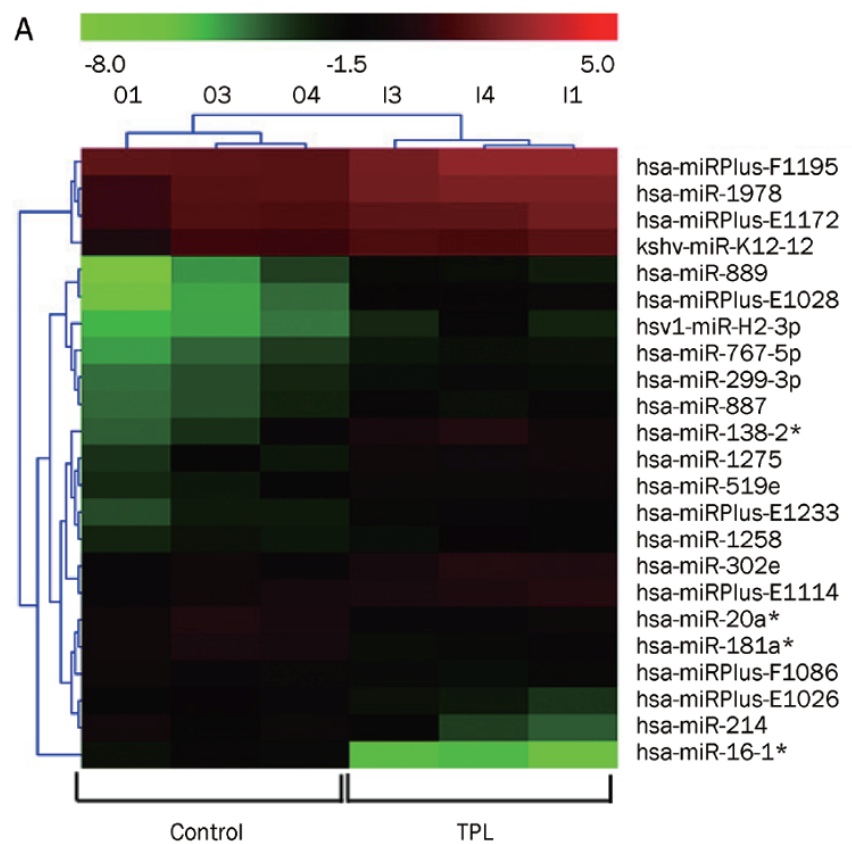

B

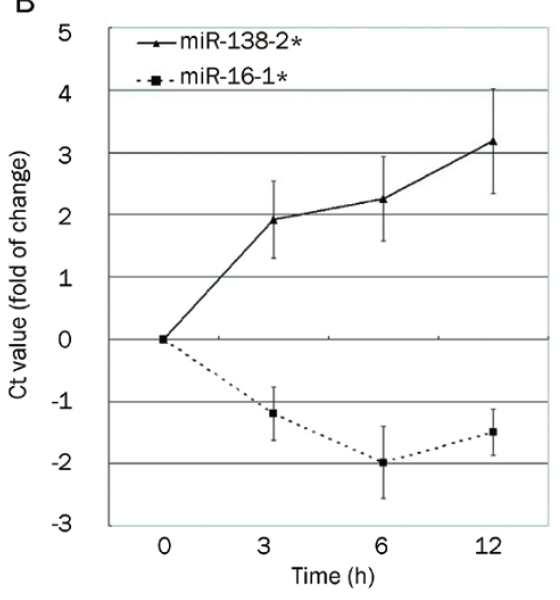

C

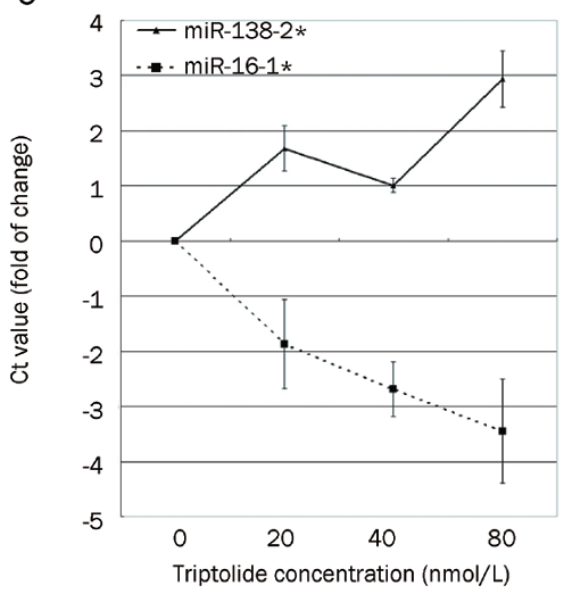

Figure 4. Triptolide affects microRNA (miRNA) expression. (A) Molt- 4 cells were treated with triptolide at $80 \mathrm{nmol} / \mathrm{L}$ for $8 \mathrm{~h}$. Total RNA was collected and then comparative analysis of miRNA expression profile was performed $(n=3)$. The color scale shown at the top illustrates the relative expression level of a miRNA: red represents a high expression level; green represents a low expression level. (B) Molt-4 cells treated with $80 \mathrm{nmol} / \mathrm{L}$ triptolide for the indicated times. Real-time PCR was done for the detection of miR-16-1* and miR-138-2* expression. (C) Real-time PCR results from Molt- 4 cells treated with triptolide at the indicated concentrations for $8 \mathrm{~h}$. (D) Levels of miR-16-1* and miRNA-138-2* in Jurkat cells treated with triptolide at the indicated concentrations for $8 \mathrm{~h}$ were determined by real-time PCR. The data in panel $B, C$, and $D$ represent the mean $\pm S D$ of three independent experiments; bars, SD. Ct value means cycle threshold value.

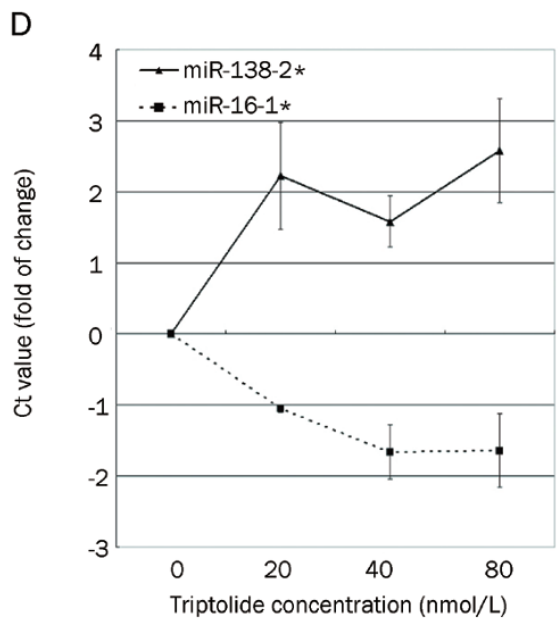

nuclear accumulation of NF-kB p65. In contrast, similar results were not found in L428 cells, which are resistant to TPL and bortezomib. Together, these data suggest that the ability of TPL to inhibit NF-KB could explain the underlying mechanism.

Previous studies suggest that cellular effects and mechanisms of action of TPL in cancer cells are highly complex and undoubtedly involve multiple biological pathways. In addition to NF-kB inhibition, down-regulation of XIAP ${ }^{[45,46]}$, activation of functional p53 pathway ${ }^{[9]}$, inhibition of Bcr-abl transcription ${ }^{[5,6]}$, and decreased HSP70 mRNA and protein levels ${ }^{[47,48]}$ are also responsible for TPL-induced cell death. In this study, we performed miRNA expression profiling using Molt- 4 cells with or without TPL treatment, and we showed that 23 miRNA genes were differentially expressed at a level of $P<0.05$. The function of majority of the identified miRNA genes, however, is still unknown. We thus focused on miR16-1* and miR-138-2*, as miR-16 and miR-138 are reported to be functionally associated with the apoptosis of cancer cells ${ }^{[39,49]}$. The results of qRTPCR, which are consistent with our microarray data, showed that TPL treatment decreased miR-16-1* expression and increased miR-138-2*. Furthermore, functional analysis revealed that miR-16-1* could partly abrogate the effects of TPL in Molt- 4 cells, suggesting that inhibition of miR-16-1* expression may contribute to TPLinduced cell death. The miR-16 family contains miRNAs that have been shown to regulate $\mathrm{Bcl}-2^{[49]}$ and cell cycle genes ${ }^{[50,51]}$, including cyclin D1, cyclin D3, cyclin E1, and CDK6, which together can result in cell cycle arrest and the apoptosis of cancer cells. Recently, miR-16-1 has been considered as a possible tumor suppressor gene ${ }^{[38]}$ because its levels have been found to be reduced or completely ablated in $>65 \%$ of CLL cases examined ${ }^{[52,53]}$. Also, forced expression of this gene can induce apoptosis through the targeting of Bcl- $2^{[49]}$. Although it remains unclear why miR-16-1*, a miR-16 family member, acts in a functionally different manner than miR-16-1, these seem- 


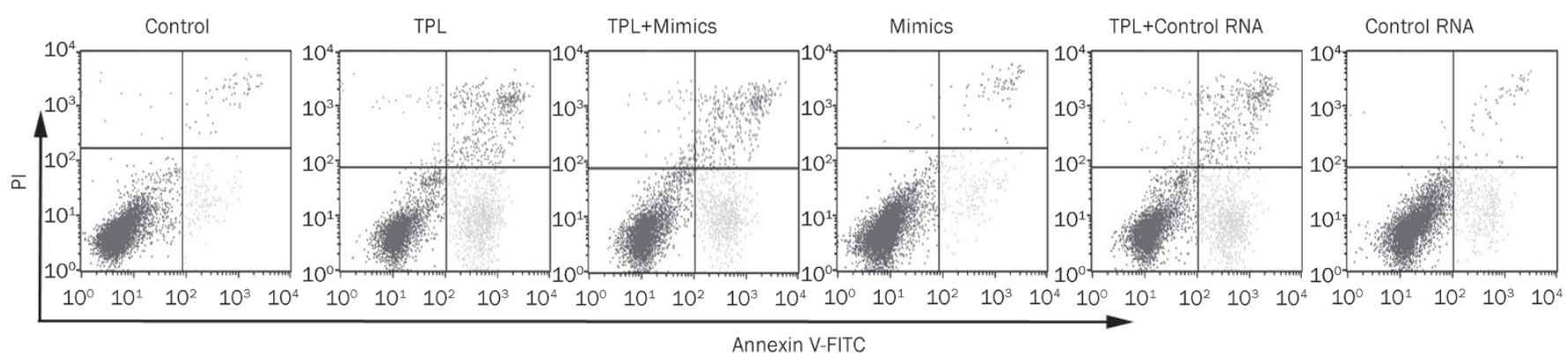

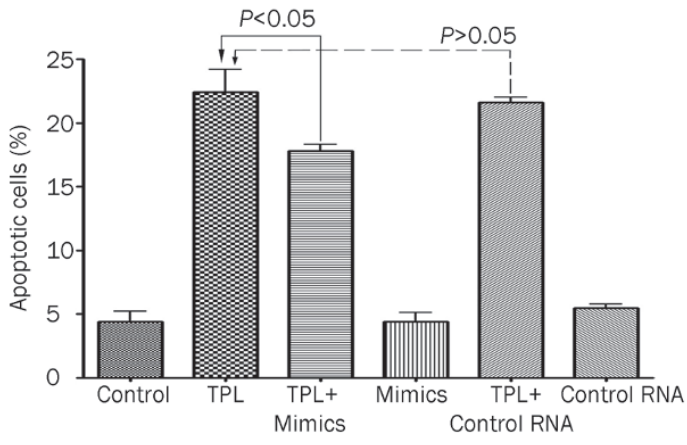

ingly contradictory findings are not surprising. In fact, CLL patients presenting with deletions of $13 q 14$, where miR-15a and miR-16-1 reside, have been shown to exhibit a more favorable prognosis ${ }^{[54]}$. In contrast, Calin et al ${ }^{[52]}$ reported that high expression levels of miR-16-1/miR-16-2 were observed in CLL patients with a poor prognosis. Taken together, these data indicate that the roles of alterations in the miR-16 family genes in the leukemia are complicated. Here, we also show that TPL up-regulates the expression of miR-138-2*. It was previously reported that miR-138, which can repress hTERT mRNA, was down-regulated in thyroid cancer cells ${ }^{[40]}$. A recent study shows that miR-138 suppresses invasion and promotes apoptosis in head and neck squamous cell carcinoma cell lines and suggests that miR-138-1 and miR-138-2 may function as tumor suppressor genes ${ }^{[39]}$. Thus, further investigation is required for evaluating the roles of miR-138-2* in TPL-induced cell death.

In summary, our data suggest that TPL at low nanomolar concentrations can potently inhibit cell growth and induce apoptosis in T-cell lymphocytic leukemia cells and that the inhibition of NF-kB may, in part, contribute to the toxicity of TPL. Additionally, TPL treatment resulted in the marked alteration of 23 miRNA genes. Among these genes, miR-1382 * expression was up-regulated and miR-16-1* was downregulated. As this may contribute to the cytotoxic effects of TPL, our data suggest that miRNAs could be a potential target for T-cell leukemia treatment. Future work is required to gain a deeper understanding of the proteins targeted by these miRNAs.

\section{Acknowledgements}

This work was supported by the National key Technology R\&D Program for the 11th Five-Year plan (№ 2008BAI61B01); Zhejiang Provincial Natural Science Foundation of China (No
Figure 5. miR-16-1* influences apoptosis induced by TPL in Molt-4 cells. The miR-16-1* mimic and negative control miRNA mimic were introduced into the Molt-4 cells. Cells transfected with or without the mimics were treated with TPL at $80 \mathrm{nmol} / \mathrm{L}$ for $12 \mathrm{~h}$. PBS was used as a vehicle control. Apoptosis was measured using flow cytometry after annexin-V/PI-staining. Data represent averages of three experiments (mean $\pm S D$ ).

\section{R2090392).}

\section{Author contribution}

Wen-bin QIAN designed the research; Hai-tao MENG, Li ZHU, Wan-mao NI, Liang-shun YOU, and Jie JIN performed the research; and Wen-bin QIAN and Li ZHU analyzed the data and wrote the paper.

\section{References}

1 Chen BJ. Triptolide, a novel immunosuppressive and anti-inflammatory agent purified from a Chinese herb Tripterygium wilfordii Hook F. Leuk Lymphoma 2001; 42: 253-65.

2 Tao XL, Sun Y, Dong Y, Xiao YL, Hu DW, Shi YP, et al. A prospective, controlled, double-blind, cross-over study of Tripterygium wilfodii hook $\mathrm{F}$ in treatment of rheumatoid arthritis. Chin Med J (Engl) 1989; 102: 327-32.

3 Shamon LA, Pezzuto JM, Graves JM, Mehta RR, Wangcharoentrakul $\mathrm{S}$, Sangsuwan R, et al. Evaluation of the mutagenic, cytotoxic, and antitumor potential of triptolide, a highly oxygenated diterpene isolated from Tripterygium wilfordii. Cancer Lett 1997; 112: 113-7.

4 Carter BZ, Mak DH, Schober WD, McQueen T, Harris D, Estrov Z, et al. Triptolide induces caspase-dependent cell death mediated via the mitochondrial pathway in leukemic cells. Blood 2006; 108: 630-7.

5 Lou YJ, Jin J. Triptolide down-regulates bcr-abl expression and induces apoptosis in chronic myelogenous leukemia cells. Leuk Lymphoma 2004; 45: 373-6.

6 Shi X, Jin Y, Cheng C, Zhang H, Zou W, Zheng Q, et al. Triptolide inhibits Bcr-Abl transcription and induces apoptosis in STI571-resistant chronic myelogenous leukemia cells harboring T315I mutation. Clin Cancer Res 2009; 15: 1686-97.

7 Yinjun L, Jie J, Yungui W. Triptolide inhibits transcription factor NFkappaB and induces apoptosis of multiple myeloma cells. Leuk Res 2005; 29: 99-105.

8 Lu LH, Lian YY, He GY, Lin SP, Huan SH, Chen ZZ, et al. Clinical study of triptolide in treatment of acute leukemia. Clin Exp Investig Hematol 
1992; 3: 1-3.

9 Kiviharju TM, Lecane PS, Sellers RG, Peehl DM. Antiproliferative and proapoptotic activities of triptolide (PG490), a natural product entering clinical trials, on primary cultures of human prostatic epithelial cells. Clin Cancer Res 2002; 8: 2666-74.

10 Harousseau JL, Dombret H, Pigneux A, Michallet M, Brandely M. Phase I study of F60008, a triptolide derivative, in patients with refractory or relapsing acute leukemias. Haematologica 2008; 93(s1): 14 abs. 0038.

11 Karin M, Lin A. NF-kappaB at the crossroads of life and death. Nat Immunol 2002; 3: 221-7.

12 Baud V, Karin M. Is NF-kappaB a good target for cancer therapy? Hopes and pitfalls. Nat Rev Drug Discov 2009; 8: 33-40.

13 Lounnas N, Frelin C, Gonthier N, Colosetti P, Sirvent A, Cassuto JP, et al. NF-kappaB inhibition triggers death of imatinib-sensitive and imatinib-resistant chronic myeloid leukemia cells including T315I BcrAbl mutants. Int J Cancer 2009; 125: 308-17.

14 Guzman ML, Rossi RM, Neelakantan S, Li X, Corbett CA, Hassane DC, et al. An orally bioavailable parthenolide analog selectively eradicates acute myelogenous leukemia stem and progenitor cells. Blood 2007; 110: 4427-35.

15 Staudt LM. The molecular and cellular origins of Hodgkin's disease. J Exp Med 2000; 191: 207-12.

16 Rosenwald A, Wright G, Chan WC, Connors JM, Campo E, Fisher RI, et al. Lymphoma/Leukemia Molecular Profiling Project. The use of molecular profiling to predict survival after chemotherapy for diffuse large-B-cell lymphoma. N Engl J Med 2002; 346: 1937-47.

17 Kordes U, Krappmann D, Heissmeyer V, Ludwig WD, Scheidereit C. Transcription factor NF-kappaB is constitutively activated in acute lymphoblastic leukemia cells. Leukemia 2000; 14: 399-402.

18 Zhao WL. Targeted therapy in T-cell malignancies: dysregulation of the cellular signaling pathways. Leukemia 2010; 24: 13-21.

19 Cardoso BA, Gírio A, Henriques C, Martins LR, Santos C, Silva A, et al. Aberrant signaling in T-cell acute lymphoblastic leukemia: biological and therapeutic implications. Braz J Med Biol Res 2008; 41: 344-50.

20 Guzman ML, Neering SJ, Upchurch D, Grimes B, Howard DS, Rizzieri $\mathrm{DA}$, et al. Nuclear factor-kappaB is constitutively activated in primitive human acute myelogenous leukemia cells. Blood 2001; 98: 2301-7.

21 dos Santos NR, Williame M, Gachet S, Cormier F, Janin A, Weih D, et al. RelB-dependent stromal cells promote T-cell leukemogenesis. PLoS ONE 2008; 3: e2555.

22 Tracey L, Streck CJ, Du Z, Williams RF, Pfeffer LM, Nathwani AC, et al. NF-kappaB activation mediates resistance to IFN beta in MLL-rearranged acute lymphoblastic leukemia. Leukemia 2010; 24: 806-12.

23 Ambros V. The evolution of our thinking about microRNAs. Nat Med 2008; 14: 1036-40.

24 Nicoloso MS, Spizzo R, Shimizu M, Rossi S, Calin GA. MicroRNAs-the micro steering wheel of tumour metastases. Nat Rev Cancer 2009; 9: 293-302.

25 Leung AK, Sharp PA. MicroRNAs: a safeguard against turmoil? Cell 2007; 130: 581-5.

26 Mi S, Lu J, Sun M, Li Z, Zhang H, Neilly MB, et al. MicroRNA expression signatures accurately discriminate acute lymphoblastic leukemia from acute myeloid leukemia. Proc Natl Acad Sci U S A 2007; 104: 199716.

27 Gaur A, Jewell DA, Liang Y, Ridzon D, Moore JH, Chen C, et al. Characterization of microRNA expression levels and their biological correlates in human cancer cell lines. Cancer Res 2007; 67: 2456-68.

28 Cho WC. MicroRNAs: potential biomarkers for cancer diagnosis, prognosis and targets for therapy. Int J Biochem Cell Biol 2010; 42: 1273-81.
29 Cho WC. MicroRNAs in cancer-form research to therapy. Biochim Biophys Acta 2010; 1805: 209-17.

30 Calin GA, Dumitru CD, Shimizu M, Bichi R, Zupo S, Noch E, et al. Frequent deletions and down-regulation of micro- RNA genes miR15 and miR16 at 13q14 in chronic lymphocytic leukemia. Proc Natl Acad Sci U S A 2002; 99: 15524-9.

31 Climent J, Dimitrow P, Fridlyand J, Palacios J, Siebert R, Albertson DG, et al. Deletion of chromosome 11q predicts response to anthracycline-based chemotherapy in early breast cancer. Cancer Res 2007; 67: 818-26.

32 Kovalchuk O, Filkowski J, Meservy J, Ilnytskyy Y, Tryndyak VP, Chekhun VF, et al. Involvement of microRNA-451 in resistance of the MCF-7 breast cancer cells to chemotherapeutic drug doxorubicin. Mol Cancer Ther 2008; 7: 2152-9.

33 Yang H, Kong W, He L, Zhao JJ, O'Donnell JD, Wang J, et al. MicroRNA expression profiling in human ovarian cancer: miR-214 induces cell survival and cisplatin resistance by targeting PTEN. Cancer Res 2008; 68: 425-33.

34 Qian W, Liu J, Tong Y, Yan S, Yang C, Yang M, et al. Enhanced antitumor activity by a selective conditionally replicating adenovirus combining with MDA-7/interleukin-24 for B-lymphoblastic leukemia via induction of apoptosis. Leukemia 2008; 22: 361-9.

35 Yang C, Tong Y, Ni W, Liu J, Xu W, Li L, et al. Inhibition of autophagy induced by overexpression of MDA/Interleukin-24 using a PI3K inhibitor results in significant enhanced antileukmia activity in vivo. Cancer Gene Ther 2010; 17: 109-19.

36 Eisen MB, Spellman PT, Brown PO, Botstein D. Cluster analysis and display of genome-wide expression patterns. Proc Natl Acad Sci U S A 1998; 95: 14863-8.

37 Harikumar KB, Kunnumakkara AB, Ahn KS, Anand P, Krishnan S, Guha $S$, et al. Modification of the cysteine residues in IkappaBalpha kinase and NF-kappaB (p65) by xanthohumol leads to suppression of NF-kappaB-regulated gene products and potentiation of apoptosis in leukemia cells. Blood 2009; 113: 2003-13.

38 Calin GA, Cimmino A, Fabbri M, Ferracin M, Wojcik SE, Shimizu M, et al. MiR-15a and miR-16-1 cluster functions in human leukemia. Proc Natl Acad Sci U S A 2008; 105: 5166-71.

39 Liu X, Jiang L, Wang A, Yu J, Shi F, Zhou X. MicroRNA-138 suppresses invasion and promotes apoptosis in head and neck squamous cell carcinoma cell lines. Cancer Lett 2009; 286: 217-22.

40 Santarpia L, Nicoloso M, Calin GA. MicroRNAs: a complex regulatory network drives the acquisition of malignant cell phenotype. Endocr Relat Cancer 2010; 17: F51-75.

41 Mori N, Fujii M, Ikeda S, Yamada Y, Tomonaga M, Ballard DW, et al. Constitutive activation of NF-kB in primary adult T-cell leukemia cells. Blood 1999; 93: 2360-8.

42 Satou Y, Nosaka K, Koya Y, Yasunaga JI, Toyokuni S, Matsuoka M. Proteasome inhibitor, bortezomib, potently inhibits the growth of adult T-cell leukemia cells both in vivo and in vitro. Leukemia 2004; 18 : 1357-63.

43 Mori N, Yamada Y, Ikeda S, Yamasaki Y, Tsukasaki K, Tanaka Y, et al. Bay 11-7082 inhibits transcription factor NF-KB and induces apoptosis of HTLV-I-infected T-cell lines and primary adult T-cell leukemia cells. Blood 2002; 100: 1828-34.

44 Qiu D, Zhao G, Aoki Y, Shi L, Uyei A, Nazarian S, et al. Immunosuppressant PG490 (triptolide) inhibits T-cell interleukin-2 expression at the level of purine-box/nuclear factor of activated T-cells and NF-KB transcriptional activation. J Biol Chem 1999; 274: 13443-50.

45 Carter BZ, Mak DH, Schober WD, Dietrich MF, Pinilla C, Vassilev LT, et al. Triptolide sensitizes AML cells to TRAIL-induced apoptosis via decrease of XIAP and p53-mediated increase of DR5. Blood 2008; 111: 
3742-50.

46 Choi YJ, Kim TG, Kim YH, Lee SH, Kwon YK, Suh SI, et al. Immunosuppressant PG490 (triptolide) induces apoptosis through the activation of caspase-3 and down-regulation of XIAP in U937 cells. Biochem Pharmacol 2003; 66: 273-80.

47 Westerheide SD, Kawahara TL, Orton K, Morimoto RI. Triptolide, an inhibitor of the human heat shock response that enhances stressinduced cell death. J Biol Chem 2006; 281: 9616-22.

48 Phillips PA, Dudeja V, McCarroll JA, Borja-Cacho D, Dawra RK, Grizzle WE, et al. Triptolide induces pancreatic cancer cell death via inhibition of heat shock protein 70. Cancer Res 2007; 67: 9407-16.

49 Cimmino A, Calin GA, Fabbri M, lorio MV, Ferracin M, Shimizu M, et al. MiR-15 and miR-16 induce apoptosis by targeting BCL2. Proc Natl Acad Sci U S A 2005; 102: 13944-9.
50 Wang F, Fu XD, Zhou Y, Zhang Y. Down-regulation of the cyclin E1 oncogene expression by microRNA-16-1 induces cell cycle arrest in human cancer cells. BMB Rep 2009; 42: 725-30.

51 Liu Q, Fu H, Sun F, Zhang H, Tie Y, Zhu J, et al. MiR-16 family induces cell cycle arrest by regulating multiple cell cycle genes. Nucleic Acids Res 2008; 36: 5391-404.

52 Calin GA, Ferracin M, Cimmino A, Di Leva G, Shimizu M, Wojcik SE, et al. A microRNA signature associated with prognosis and progression in chronic lymphocytic leukemia. N Engl J Med 2005; 353: 1793-801.

53 Calin GA, Liu CG, Sevignani C, Ferracin M, Felli N, Dumitru CD, et al. MicroRNA profiling reveals distinct signatures in B cell chronic lymphocytic leukemias. Proc Natl Acad Sci U S A 2004; 101: 11755-60.

54 Caligaris-Cappio F, Hamblin TJ. B-cell chronic lymphocytic leukemia: a bird of a different feather. J Clin Oncol 1999; 17: 399-408. 